\title{
Design of an Automatic Bell Warning System for Prayer Times in A Net-Centric Computing $\mathrm{Lab}$
}

\author{
Juhariansyah $^{1}$, Ritzkal ${ }^{2}$, Ade Hendri Hendrawan ${ }^{3}$ \\ 1, 2, 3 Net-Centric Computing Laboratory, Informatics Engineering Study Program, Faculty of Engineering \& \\ Science, Ibn Khaldun University, Bogor. Indonesia \\ juhariansyah13@gmail.com¹, ritzkal@ft.uika-bogor.ac.id ${ }^{2}$, hendri@uika-bogor.ac.id ${ }^{3}$
}

\begin{abstract}
The development of science and technology has been increasing rapidly, providing convenience in everyday life. Various household appliances and office work tools use electronic devices to ease the works, including bell warning systems for prayer times. The system notifies the people when the times for prayer comes. The warning systems used presently have not operated automatically. The research aimed to design and implement a series of automatic warning bell system for prayer times, that sent a notification to the telegram. It used Arduino Mega 2560 as the data processor. The result found that the tool, equipped with an RTC, a Dfplayer, a loud-speaker, and an Ethernet Shield, worked satisfactorily by sending a notification to the Telegram.
\end{abstract}

Keywords-RTC, Dfplayer, Telegram, Arduino.

\section{INTRODUCTION}

Nowadays, almost all things have been relating to science and technology, machines or electronics, that make the works be done easily without having to waste energy. Various applied technology ranges from household appliances to office work used in everyday life to facilitate people in their daily life. One of the technological developments is a warning system. The warning system is a series of systems or tools to collect information, useful for a surveillance system.

Several researchers have researched warning systems using a microcontroller. Ando developed a distributed monitoring system for structural early warning. It was a lowcost approach to structural and seismic monitoring to develop an early warning system [1]. Ibrahim designed and implemented a GSM-based digital door lock security system using a PIC platform [2]. Panicker performed monitoring of vital signals in real-time through telemedicine for public health care. The system included the continuous collection of physiological parameters (blood pressure, pulse) in real-time and wireless transmission to a tablet PC that could be monitored for diagnosis by medical practitioners [3]. The important task of detecting and monitoring pollution initiated Raipure to investigate a pollution monitoring system based on wireless sensor networks in metropolitan cities [4]. Galvani designed a prototype of a microcontroller-based Odometer reading for early warning in-vehicle lubricant replacement. An Odometer is an instrument to measure vehicle mileage and usually used for periodic inspection of vehicle lubricant replacement [5].
Most health institutions and public hospitals use continuous, large, and heavy, continuous heart monitoring machines that are not equipped with the option to send alerts if there are alarming changes in the patient's heart rate. Hence, a mobile heart detection system (MoHeRDS) for early warning of potential-fatal heart Disease was investigated by Rosli to overcome the problem [6]. A medical warehouse monitoring and control system using LabVIEW was researched by Chuan that monitored and controlled systems for medical warehouses to ensure that drugs in warehouses were maintained within an acceptable temperature and humidity limits [7]. Collision warning and avoidance are good things established in research for the automotive industry. It inspired Van Brummelen to investigate a reliable and inexpensive cyclist collision warning system for safer travel on urban roads [8]. The development of a microcontroller-based landslide early warning system was investigated by Fernandez. As reported by the Philippine national disaster risk reduction coordinating council, from 2010-2015, landslides were the third most recurring geohazard after floods and earthquakes [9]. Tsourma developed a hybrid defensive embedded system with facial recognition. The rapid development of the Internet of Things and the current capabilities of high-performance embedded systems have made them more attractive for the replacement of human personnel in dangerous or tedious tasks [10].

Environmental monitoring is such an interesting system and plays an important role in human life. The design of wireless sensor networks for landslide warning systems in the IoT architecture was investigated by Sofwan. Landslides frequently occur in Indonesia, which has climate characteristics, regional topography, and geological structures that make this country bear many landslide potential areas [11]. A landmine robot controlled by Arduino was examined by Abilash to detect landmines. Landmines were widely used during warfare. It was necessary to use motorized vehicles in the landmines area to detect them for safety reasons [12]. Investigation on the avoidance of pedestrian collisions with car brakes was carried out by Avinash. The researcher analyzed the safety system to avoid collisions between vehicles and pedestrians using warning signals and automatic braking of vehicles [13]. The Internet of Things (IoT) to measure and monitor sensor data for surface water platforms was studied by Kafli [14]. Some 
fishermen only after getting as many fish as possible without paying attention to the damage they do to the environment. Hence, Avenando design and implemented the detection of underwater explosions by SMS prompt [15].

Dabir studied and examined GPS and IoT equipped with a smart walking stick to avoid falls for older people. The system consisted of an obstacle detection module, a fall detection module, and a pulse monitoring-cum-alert module. The Raspberry-Pi based system was mounted on a tripod walking stick that aided the vulnerable to be connected with their family in times of distress [16]. Lichtman researched an intelligent electrocardiogram monitoring system on Android. An electrocardiogram is an electrical record of cardiac activity used for diagnostics and can help detect people when sleeping or having a heart attack based on their heart rate [17]. Sandhyavitri investigated an early warning system using a fire sensor, wireless, and SMS technology. The purpose of the research was to explore the state of the art in developing a package of early warning systems in peat fire disaster mitigation [18]. Devaraj Sheshu implemented a flood warning system using IoT by detecting the water flow rate using IR sensors and water levels using Ultrasonic sensors in rivers and waterways and sending the data via Wi-Fi to the main controller. The main controller then checked the received sensor values, and when the value varied outside a certain threshold, an alarm (buzzer) and a Short Message Service (SMS) were sent to mobile phones [19]. Lai examined a car door security system with wireless warning transmission. The car door security system had two main features, namely sensory objects when the car door opened, indicated with audio and visible light warnings, and low power wireless communication whose technology based on IEEE 802.11ah named Sigfox that gave a warning when an accident was detected [20].

A warning is generally an act of providing information in an easily digestible language, for example, manifested in the form of an alarm or siren. An alarm or siren is a form of information delivery, including an automatic school bell. The automatic school bell is activated by a schedule control system with an Arduino Uno microcontroller. It automatically activates according to the school bell schedule input, which has been programmed so that the teacher in charge to ring the bell no longer does it manually.

As the school bell, a warning system for prayer times has not used warning systems automatically. The Net-Centric Computing Laboratory in the University of Ibn Khaldun Bogor (UIKA), still does not use an automatic bell system. Sometimes the students, busy with the campus activities or works, confuse whether it is the time for prayer or not. It inspired the author to design an automatic warning for prayer times.

Information technology has developed rapidly at this time, especially with the existence of internet networks that can facilitate communication with other parties. In the last two decades, computer networks have become a revolutionary field for improvisation in which the information and data move through wires or wireless devices, allowing computer network users to exchange documents and data. The research aims at developing an automatic warning system for prayer times that can send notifications using internet technology through social media telegram.

\section{METHODS}

Figure 1 displays that the RTC DS3231 [21]-[24], Dfplayer is an input, and the Arduino Mega 2560 [21], [25][27] is a process and directly transmitted to the LCD and speaker, which has been set as an output.

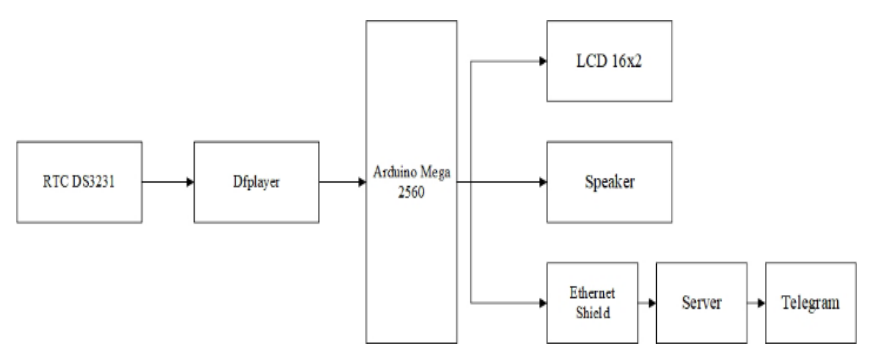

Fig. 1. System block diagram

The RTC set the clock, and the Dfplayer played the "Adzan", a sound file stored in the memory card. The LCD on the microcontroller [22], [28]-[30] displays the words "it is time for prayer," and the speaker says them aloud. The microcontroller then instructs the Ethernet shield to send it to the server and the telegram [31][32].

\section{A. Hardware system}

Figure 2 illustrates that the circuit is divided into several stages, namely, the first stage of the Dfplayer schematic circuit connected to the Arduino at pin 7.8, GND, 5V consisting of pin 7 to $\mathrm{TX}$ (transmitter) and pin 8 to $\mathrm{RX}$ (receiver), GND pin, and pin 5V. The two Arduino schematic circuits are connected to the RTC (real-time clock) on the SDA 20 pin (serial data), SCL 21 (serial clock), GND, 5V consisting of SDA 20 SDA, SCL 21 SCL GND, and pin 5V. All three schematic circuits Arduino are connected to the LCD (liquid crystal display). The output pins of Arduino Mega that will be used are GND, VCC, SDA, SCL pins consisting of GND, VCC, SDA, and SCL.

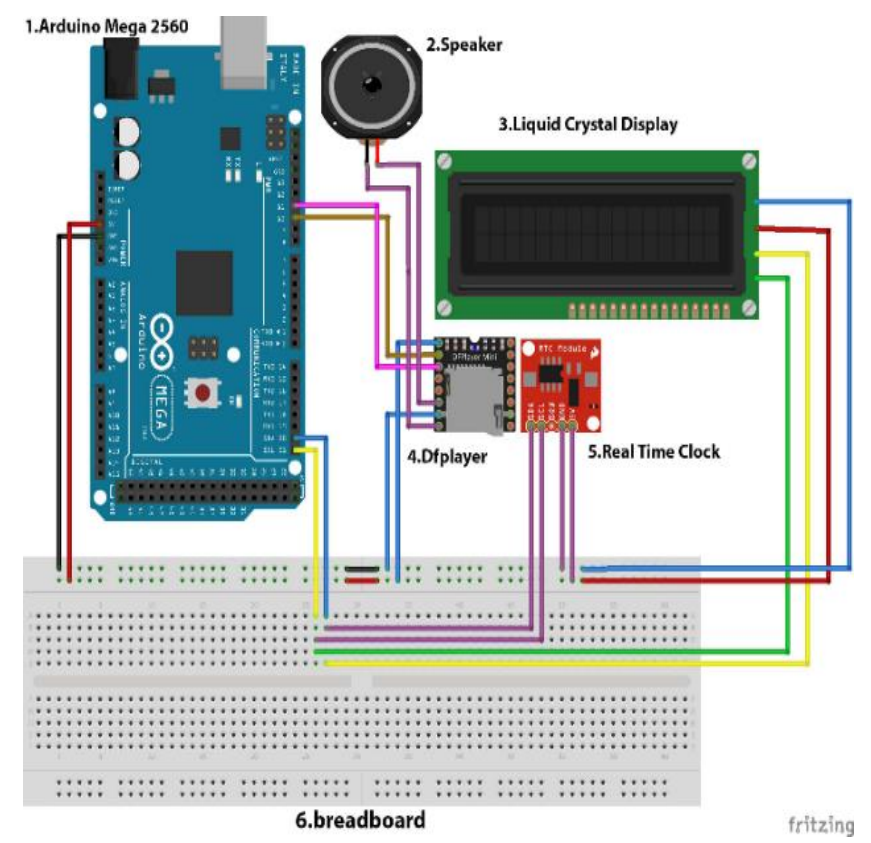

Fig. 2. Wiring diagram 


\section{B. System workflow program}

Figure 3 displays the system workflow. It shows how the motion system works based on their respective functions on each device and material that has been run. The first system gets the time data from RTC. Then, if the prayer time is coming, the system will play the sound and send the notification in LCD and telegram. Normally, the system will show the date.

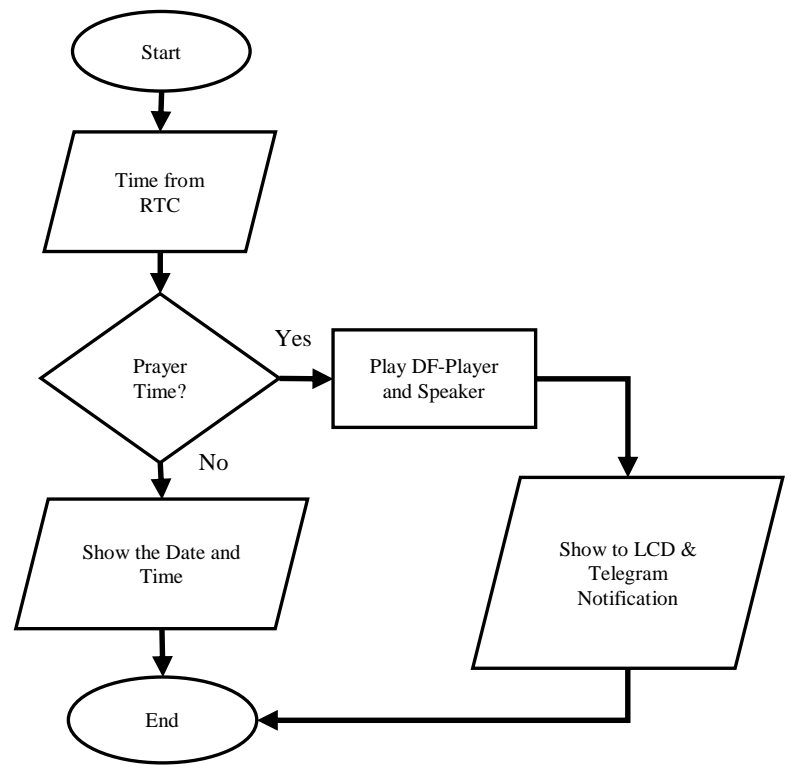

Fig. 3. System workflow diagram

\section{RESULT AND DisCUSSION}

\section{A. Work of the system}

The research started from a predetermined hour using RTC, Dfplayer to insert sound and audio files. The Arduino Mega then received the data from the Dfplayer and processed them. The speaker would sound according to the source code that had been created. The microcontroller then instructed the ethernet shield to send a notification to a private telegram whose source code or PHP had been stored in the server.

\section{B. Testing}

The testing started from predetermined hours using an RTC and a Dfplayer to insert sound and audio files. The Arduino Mega received data from Dfplayer and processed them. The speaker sounded according to the source code that had been created. The microcontroller then instructed the Ethernet shield to send a notification to a private telegram whose source code or PHP that had been stored in the RTC server.

The testing before the prayer time is shown in Figure 4. Based on the figure, it can be known that the system can show the date and time.

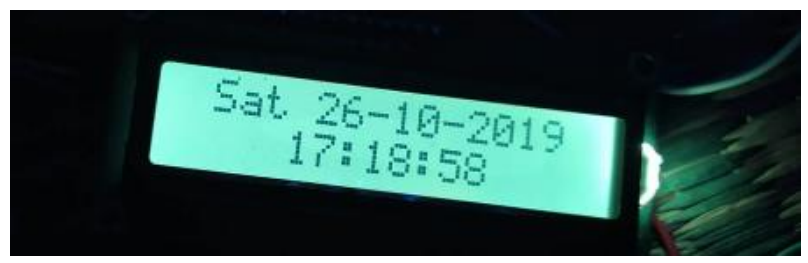

Fig. 4. Testing before prayer time

\section{LCD (Liquid Crystal Display)}

LCD testing is done to display notification messages automatically to the LCD, to prepare for prayer time to arrive. The result is shown in Figure 5. Based on the figure, it can be known that the LCD can show the player text.

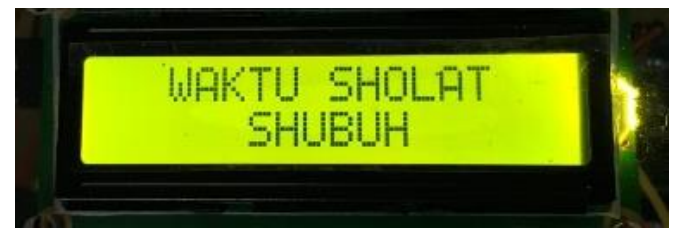

Fig. 5. LCD testing

\section{Telegram testing}

The Telegram testing was carried out to send a notification message automatically to the telegram when the prayer time came. Figure 6 Telegram testing according to the automatic schedule system. It can be known that the telegram can receive the message. Thus the system can work well.

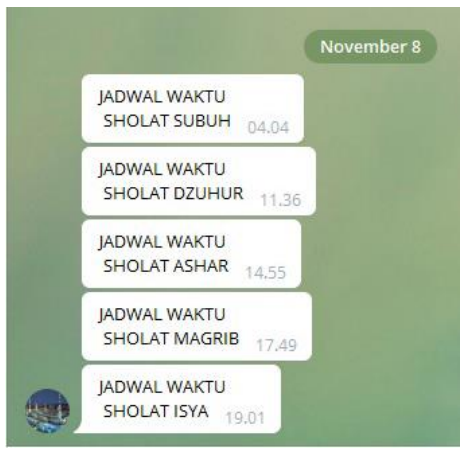

Fig. 6. Telegram Testing

\section{CONCLUSION}

Based on results and discussion in the article, it is found that the utilization of Arduino microcontroller as a core data processing tool in the design of the warning system for prayer times has worked properly and satisfactorily. The results demonstrated that the automatic alert system successfully sends a notification to the Telegram when the prayer time has come. The application is functioning per intended design, and meeting the overall project objectives.

\section{REFERENCES}

[1] B. Ando, S. Baglio, and A. Pistorio, "A distributed monitoring systems for structural early warning," in 2015 IEEE International Workshop on Measurements \& Networking (M\&N), 2015, pp. 1-5.

[2] A. Ibrahim, A. Paravath, P. K. Aswin, S. M. Iqbal, and S. U. Abdulla, "GSM based digital door lock security system," in 2015 International Conference on Power, Instrumentation, Control and Computing (PICC), 2015, pp. 1-6.

[3] N. V. Panicker and Sukesh Kumar A, "Real time monitoring of vital signals through telemedicine for community healthcare," in 2015 International Conference on Control Communication \& Computing India (ICCC), 2015, no. November, pp. 362-365.

[4] S. Raipure and D. Mehetre, "Wireless sensor network based pollution monitoring system in metropolitan cities," in 2015 International Conference on Communications and Signal Processing (ICCSP), 2015, pp. 1835-1838.

[5] A. Galvani, A. Rakhmatsyah, and G. A. Mutiara, "Prototype of microcontroller-based odometer reading for early warning in the vehicle lubricants replacement," in 2015 3rd International 
Conference on Information and Communication Technology (ICoICT), 2015, pp. 172-177.

[6] R. S. B. Rosli and R. F. Olanrewaju, "Mobile Heart Rate Detection System (MoHeRDS) for Early Warning of Potentially-Fatal Heart Diseases," in 2016 International Conference on Computer and Communication Engineering (ICCCE), 2016, pp. 422-427.

[7] O. W. Chuan and S. H. Ruslan, "Medical warehouse monitoring and control system using LabVIEW," in 2016 International Conference on Electrical, Electronics, and Optimization Techniques (ICEEOT), 2016, pp. 2396-2401.

[8] J. Van Brummelen, B. Emran, K. Yesilcimen, and H. Najjaran, "Reliable and low-cost cyclist collision warning system for safer commute on urban roads," in 2016 IEEE International Conference on Systems, Man, and Cybernetics (SMC), 2016, no. 341887, pp. 003731-003735.

[9] C. D. Fernandez, K. J. A. Mendoza, A. J. S. Tiongson, and M. B. Mendoza, "Development of microcontroller-based landslide early warning system," in 2016 IEEE Region 10 Conference (TENCON), 2016, pp. 3000-3005.

[10] M. Tsourma and M. Dasygenis, "Development of a Hybrid Defensive Embedded System with Face Recognition," in 2016 IEEE Intl Conference on Computational Science and Engineering (CSE) and IEEE Intl Conference on Embedded and Ubiquitous Computing (EUC) and 15th Intl Symposium on Distributed Computing and Applications for Business Engineering (DCABES), 2016, pp. 154157.

[11] A. Sofwan, Sumardi, M. Ridho, A. Goni, and Najib, "Wireless sensor network design for landslide warning system in IoT architecture," in 2017 4th International Conference on Information Technology, Computer, and Electrical Engineering (ICITACEE), 2017, vol. 2018-Janua, pp. 280-283.

[12] V. Abilash and J. P. C. Kumar, "Ardunio controlled landmine detection robot," in 2017 Third International Conference on Science Technology Engineering \& Management (ICONSTEM), 2017, vol. 2018-Janua, pp. 1077-1082.

[13] R. Avinash, J. Niresh, V. H. Kumar, and S. Neelakrishnan, "Investigation of pedestrian collision avoidance with auto brake," in 2017 Recent Developments in Control, Automation \& Power Engineering (RDCAPE), 2017, vol. 3, pp. 477-481.

[14] N. Kafli and K. Isa, "Internet of Things (IoT) for measuring and monitoring sensors data of water surface platform," in 2017 IEEE 7th International Conference on Underwater System Technology: Theory and Applications (USYS), 2017, vol. 2018-Janua, pp. 1-6.

[15] G. O. Avendano et al., "Underwater explosion detection with SMS prompt," in 2017IEEE 9th International Conference on Humanoid, Nanotechnology, Information Technology, Communication and Control, Environment and Management (HNICEM), 2017, vol. 2018-Janua, pp. 1-5.

[16] A. Dabir, R. Solkar, M. Kumbhar, and G. Narayanan, "GPS and IOT Equipped Smart Walking Stick," in 2018 International Conference on Communication and Signal Processing (ICCSP), 2018, pp. 03220326 .

[17] A. Lichtman, R. Uzsak, M. Svetlak, and P. Fuchs, "A Smart Electrocardiogram Monitoring System on Android," in 2018 New Trends in Signal Processing (NTSP), 2018, pp. 1-5.

[18] A. Sandhyavitri, R. Amri, M. Yusa, D. Fermana, and N. D. Ali, "Early Warning Systems Using Fire Sensors, Wireless, and SMS Technology," in 2018 2nd International Conference on Electrical Engineering and Informatics (ICon EEI), 2018, no. October, pp. $108-113$.

[19] E. Devaraj Sheshu, N. Manjunath, S. Karthik, and U. Akash, "Implementation of Flood Warning System using IoT," in 2018
Second International Conference on Green Computing and Internet of Things (ICGCIoT), 2018, pp. 445-448.

[20] C.-H. Lai, C.-C. Lin, G.-L. Tsai, and Y.-S. Hwang, "The car door safety system with wireless alert transmission," in 2018 7th International Symposium on Next Generation Electronics (ISNE), 2018, no. Isne, pp. 1-3.

[21] M. Kusriyanto and A. A. Putra, "Weather Station Design Using IoT Platform Based On Arduino Mega," in 2018 International Symposium on Electronics and Smart Devices (ISESD), 2018, pp. $1-4$.

[22] P. Dangare, T. Mhizha, and E. Mashonjowa, "Design, fabrication and testing of a low cost Trunk Diameter Variation (TDV) measurement system based on an ATmega 328/P microcontroller," Comput. Electron. Agric., vol. 148, no. August 2017, pp. 197-206, 2018.

[23] D. Chalagulla, J. Jayateertha, C. R. Kudimi, P. V. Manitha, and M. Sujith, "Efficient Energy Utilization Control with Remote Network Access," in 2018 International Conference on Communication, Computing and Internet of Things (IC3IoT), 2018, pp. 262-266.

[24] J. Guaman, F. Astudillo-Salinas, A. Vazquez-Rodas, L. I. Minchala, and S. Placencia, "Water Level Monitoring System Based on LoPy4 Microcontroller with LoRa technology," in 2018 IEEE XXV International Conference on Electronics, Electrical Engineering and Computing (INTERCON), 2018, pp. 1-4.

[25] A. Holovatyy, V. Teslyuk, M. Lobur, S. Pobereyko, and Y. Sokolovsky, "Development of Arduino-Based Embedded System for Detection of Toxic Gases in Air," in 2018 IEEE 13th International Scientific and Technical Conference on Computer Sciences and Information Technologies (CSIT), 2018, vol. 1, pp. 139-142.

[26] O. Nabil, B. Bachir, and A. ALLAG, "Implementation of a new MPPT Technique for PV systems using a Boost Converter driven by Arduino MEGA," in 2018 International Conference on Communications and Electrical Engineering (ICCEE), 2018, pp. 15 .

[27] K. N. Hairol, R. Adnan, A. M. Samad, and F. Ahmat Ruslan, "Aquaculture Monitoring System using Arduino Mega for Automated Fish Pond System Application," in 2018 IEEE Conference on Systems, Process and Control (ICSPC), 2018, no. December, pp. 218-223.

[28] A. Mandal, S. Panda, and A. Goswami, "Driving a Charged Coupled Device (CCD) by microcontroller for LIBS based application," in 2018 International Symposium on Devices, Circuits and Systems (ISDCS), 2018, no. Ccd, pp. 1-5.

[29] R. Yuwono, D. F. Kurniawan, and M. Hadvan Arif, "Design of Multi Switch Operation Mode Rectenna Device for $2.4 \mathrm{GHz}$ Frequency Band Wi-Fi and Bluetooth Based On Microcontroller ATmega328," in 2018 1st International Conference on Computer Applications \& Information Security (ICCAIS), 2018, pp. 1-6.

[30] D. Parducho et al., "Smart Wound Dressing with Arduino Microcontroller," in 2018 IEEE 10th International Conference on Humanoid, Nanotechnology, Information Technology,Communication and Control, Environment and Management (HNICEM), 2018, pp. 1-4.

[31] Ritzkal, "Manajemen Jaringan untuk Pemula," UIKA Press, 2018.

[32] S. Syaiful, D. Hariyadi, "Case Study on Sustainable T-Junction Cibinong City Mall (CCM) in Bogor Indonesia, Asian Research Publishing Network (ARPN) Journal of Engineering and Applied Science, vol. 14, no. 17, 2019. 